\title{
Transgressive Sills and Lateral Lava Flows: On the Visual Observation of Igneous Sheets in Rugged Mountainous Terrains and the Optical Illusion Factor
}

\author{
Jogvan Hansen \\ Independent Researcher, Faroe Islands, Denmark \\ Email address: \\ jogvanha@olivant.fo, jogvan.hansen@dunelm.org.uk
}

To cite this article:

Jogvan Hansen. Transgressive Sills and Lateral Lava Flows: On the Visual Observation of Igneous Sheets in Rugged Mountainous Terrains and the Optical Illusion Factor. Earth Sciences. Vol. 9, No. 5, 2020, pp. 164-177. doi: 10.11648/j.earth.20200905.13

Received: August 15, 2020; Accepted: September 4, 2020; Published: September 17, 2020

\begin{abstract}
Transgressive sills are of common occurrences in rift-related offshore and onshore sedimentary settings worldwide and have been reported in onshore volcanic settings in e.g. flood basalt provinces as well. General geometries of individual sills and of entire sill complexes too are well documented from seismic images in many offshore sedimentary settings of exploration interest, but limitations in seismic resolution may inhibit correct interpretations when it comes to smallscale structures and evidences on sill intrusion modes. Hence, relevant and important details and clues on intrusion mechanisms during emplacement of sheet intrusions, which may be unclear or missing in seismic images from offshore sedimentary basins, can to some degree be clarified by means of thorough visual examination and measurements on exposed onshore sills and sill complexes. In the actual study, relevant visual observations and measurements of the Streymoy Sill and its feeders in particular and to a lesser degree the Eysturoy Sill of the Faroe Islands, as well as some local lava flows, are scrutinised in order to demonstrate the importance of correct and detailed mapping, associated measurements and interpretations at exposed sill margins. The actual study chiefly focuses on potential optical illusion factors, not uncommon for sheet intrusions in rugged mountainous terrain, and potential associated misinterpretations. It is shown that unless due care is taken in assuring that sub-horizontal visual observations from some distance in such terrains are duly accompanied by other observations in the sub-vertical and/or sub-lateral plane at other angles as well, i.e. proper 3-D considerations, noticeable errors could result, when it comes to interpretations on intrusion mechanisms and possible regional stresses that prevailed during emplacement of such sheet-like igneous bodies.
\end{abstract}

Keywords: Faroe Islands, Basaltic Rocks, Transgressive Sills, Flood Basalts, Sill Intrusion, Structural Geology

\section{Introduction}

Sills may occur in a wide variety of forms, extent and thicknesses. When it comes to sills in the upper crust, these are commonly thought of as either rather simple magma storage champers or simple conduits of magmas ascending through the crust, or they may form part of complex and intricate sill complexes capable of lateral magma transport as well as transport of magmas to storage chambers higher in the crust or to surface magmatism [1-7]. Although sill systems have most commonly been reported in rift-related or passive sedimentary settings, they are not uncommon in volcanic settings, e.g. areas affected by basaltic magmatism such as in flood basalt provinces [3]. When it comes to sills in rifted or passive sedimentary settings in offshore areas, seismic imaging associated with prospective activity has revealed the wide variety of sills in such settings, including sills as isolated bodies and internally connected sills in entire sill complexes, thus enabling geologists to estimate/interpret intrusion mechanisms prevailing in such settings [5]. The natural limitations associated with detecting small-scale structures using seismic imaging (sub-seismic structures) in offshore sedimentary settings can to some degree be compensated for by visual observations and measurements of exposed sills in onshore sedimentary and/or volcanic settings. Well known examples of examinations of onshore sills in various settings include the Karoo Basin, South Africa [8, 9], Jameson Land, East Greenland [10, 11], Iceland [12, 13], the 
Faroe Islands [3, 14-17] and the Neuquén Basin, Argentina [18].

The objective of this work is to utilise a number of visual observations/images at various angles of the actual targets at exposed margins of the sheet-like bodies of the Streymoy Sill, the Eysturoy Sill, some local lava flows and a sill feeder, which occur in rugged mountainous terrains in the Faroe Islands, in addition to structural measurements where suitable, in order to constrain and correctly estimate and interpret their true architecture.

\section{Geological Settings}

The lava pile of the Faroe Islands form a part of the North Atlantic Igneous Province (NAIP) and originally reached a maximum thickness of $\sim 6.6 \mathrm{~km}$ and currently cover an onshore area of $1400 \mathrm{~km}^{2}$ [16]. The lava successions are intruded by a number of transgressive basaltic sills, which are exposed in the three uppermost formations, namely the 1250$1350 \mathrm{~m}$ thick Malinstindur Formation, the $30 \mathrm{~m}$ thick Sneis Formation and the $900 \mathrm{~m}$ thick Enni Formation, where the total vertical extent of individual sills range from a few tens of metres to hundreds of metres (Figure 1). Individual lava flows or packages comprising several lava flows in the actual area are not uncommonly separated by reddish layers ranging in thicknesses from centimetres to tens of centimetres (occasionally even metres) consisting of sedimentary material originating from either erosive actions or from volcanic ashes [16].

Sub-vertical dykes that initially fed the lava flows are of frequent occurrences throughout the Faroese archipelago, whereas variously inclined feeder sheets are occasionally found in association with some of the exposed local sills $[15,19]$.

When it comes to the sills cropping out in the Faroe Islands, the larger of these typically display noticeable saucer-shaped geometries comparable to those, frequently displayed in seismic images from offshore sedimentary basins. The two largest sills targeted in this work (the Streymoy and Eysturoy sills) are each made up of two segments, with the preserved parts of the NW segments being from 10 to 30 metres thick and the preserved parts of SE segments being from 40 to 55 metres thick $[15,19]$.

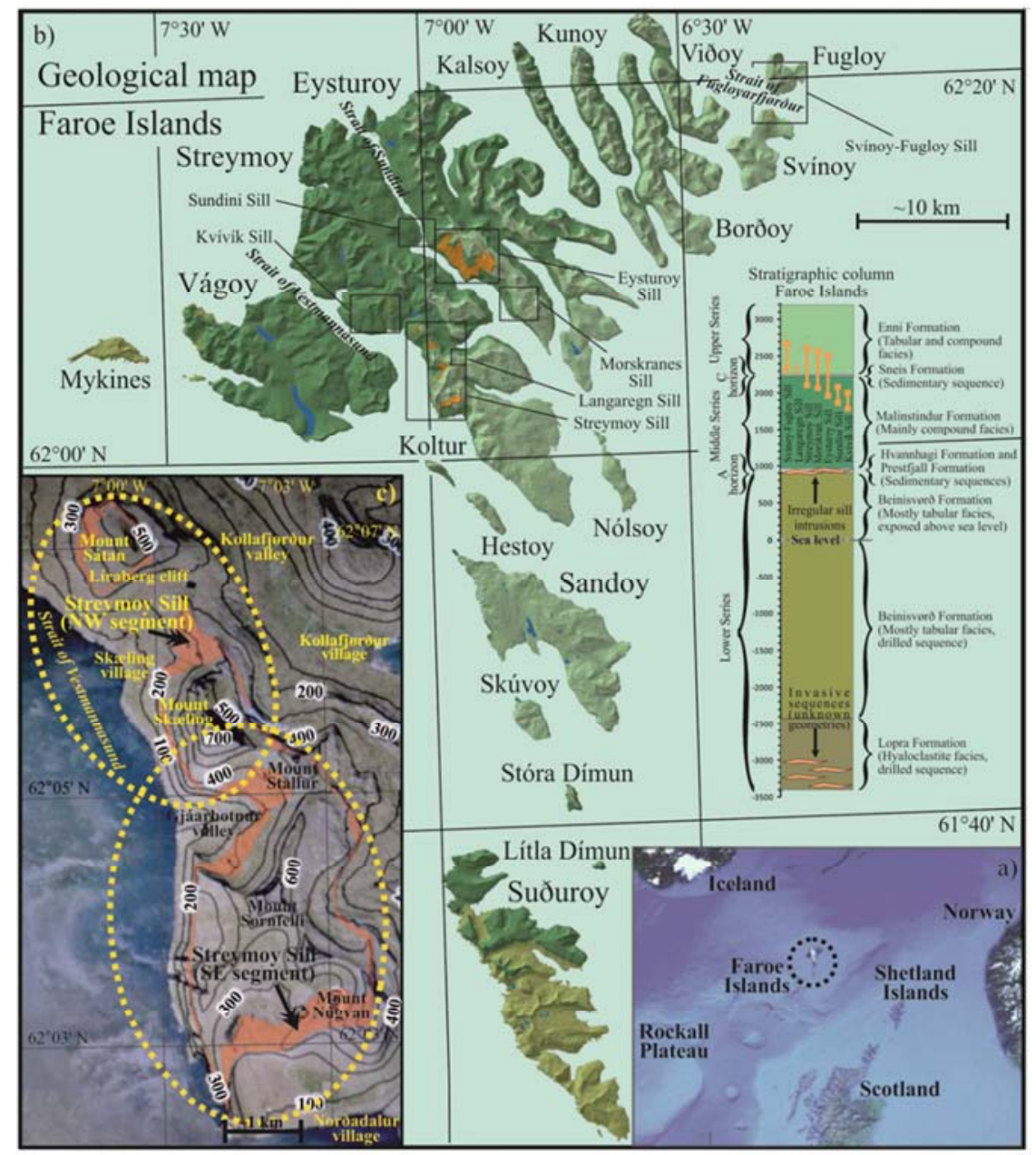

Figure 1. Modified from a previous study [16]. a) Map of the North Atlantic area showing the relative location of the Faroe Islands. Basic image from Google Earth. b) Geological map of the Faroe Islands. Older nomenclature is indicated to the right of the stratigraphic column and a more recent nomenclature is shown to the left. Vertical extents of sills are indicated by orange bars in stratigraphic column. Topographic and other map data originate from Munin.Fo. Faroe Islands. c) The map shows the two segments making up the Streymoy Sill, where sill outcrops are indicated in orange colour. Numbers on topographic contours indicate metres. Basic image from Kortal. Fo, Faroe Islands. 


\section{Previous Work and Theoretical Framework/Methods}

Two previous efforts to determine/interpret if possible syn-magmatic stresses were in action during intrusion of the Faroese Streymoy Sill in particular have come to a roughly similar conclusion, namely that the Faroese sills were emplaced during a period with a prevailing regional NE-SW to ENE-WSW compressive regime respectively, i.e. as shown in the stereo plot in Figure $2 b[14,17]$.

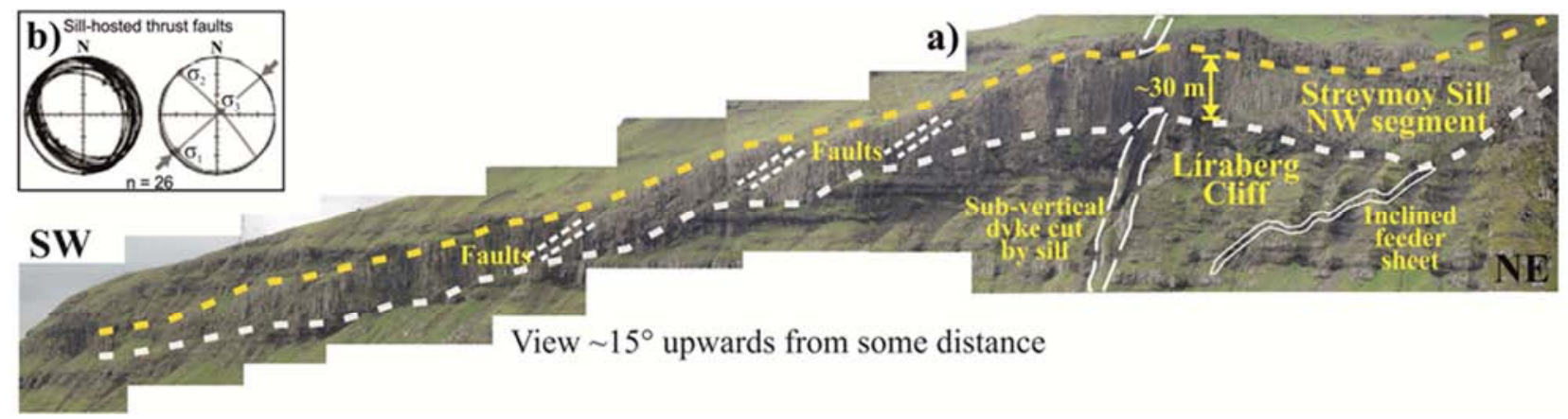

Figure 2. a) Around 1.2 kilometre outcrop of the Streymoy Sill at Liraberg Faroe Islands (see also Figure 1). White dashed line indicates verified lower sill contact, while yellow dashed line indicates verified and estimated upper sill contact. b) Stereo plots showing measurements of thrust faults hosted by the Streymoy Sill from [17].

Based on the visual features characterising the Streymoy Sill, where it crops out at the sub-vertical cliff of Líraberg Faroe Islands, as shown in Figure 2, one study came to the conclusion that parts of the actual sill and its feeder at this locality showed evidence of an intrusion mechanism that favoured transgression and ramp-flat geometries and were consistent with regional shortening, with steps indicating transitions between transgressive and lateral sill propagation controlled locally by layering [17].

Lateral sill propagation in response to differing host-rock lithologies in layered strata is indeed an intrusion mechanism that is widely accepted amongst geologists worldwide for sill emplacement in volcanic and sedimentary environments alike $[5,13,20]$. Sill deflection in response to pre-existing subvertical structures in both volcanic and sedimentary settings is a well documented mechanism too $[3,5,15]$.

Other previous studies on the sills cropping out in the lava pile of the Faroe Islands have theorised that these sills by and large were not significantly affected by the sub-horizontal layering of local host-rocks during intrusion, although the upward-curving geometries typifying these sills are not strictly perfectly continuous in all exposed outcrops $[3,15$, $19]$.

The theoretical framework for this study includes, that an additional investigation regarding the inconsistency between existing theories on intrusion mechanisms with respect to the same sills of the Faroe Islands would appear to be justified. In this work the focus will be to properly investigate and illuminate the apparent ramp-flat geometries seen in some locations of the Streymoy Sill such as those appearing in Figure 2. The methods will include conventional imaging from various angles of individual targets such as sills, feeders and local lava flows, including high-resolution aerial images of key locations at sill margins by means of drones, in order to demonstrate their geometry properly from a 3-D perspective. In addition, some measurements will be applied, including some recent structural measurements presented in stereo plots mostly on conjugate faults/fractures hosted by the Streymoy Sill.

\section{Results and Observations}

\subsection{Large-scale Sill Structures (Kilometre Scales)}

From conventional structural geology, we know that certain geological structures such as folds tend to repeat themselves at macroscopic and mesoscopic scales, in hand specimen and not uncommonly at microscopic scales as well. When it comes to the sills, cropping out in the mountainous terrains of the Faroe Islands, they too tend to display comparable structures at a number of scales as demonstrated below.

At the several kilometre sill outcrop in an area adjacent to the village of Norðadal, the transverse profile displays an almost perfect saucer-shaped geometry apart from a large rather symmetrical bulge left centre, when seen from some distance towards a NW direction (Figure 3a). However, when the same outcrop is viewed at a closer range and from higher elevation towards a WSW direction, the impression of sill geometry is somewhat different. It is abundantly clear that the apparent bulge displayed in Figure $3 \mathrm{a}$ is a consequence of a tongue-shaped protrusion emanating up-dip from lower altitudes at roughly right angles with the local strike direction, i.e. this is obviously an optical illusion effect in action, due to the image in Figure 3a being taken from afar without compensating for variations in distances to all parts of the actual profile representing this transgressive sill at this location (Figure 3b). 

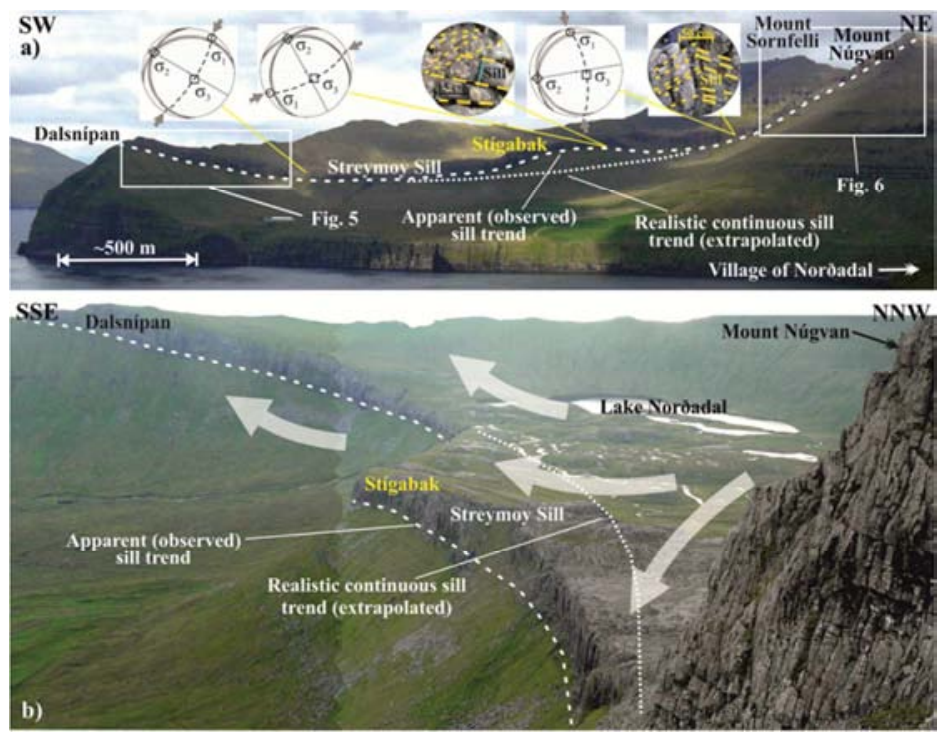

Figure 3. The images show a transverse profile of the SE segment of the Streymoy Sill in the vicinity of the village of Norðadal, as shown in Figure 1c. Lower sill margins are indicated with white dashed lines, while extrapolated lower margin sections are shown as white dotted lines. a) The transverse profile of the 3 $\mathrm{km}$ sill outcrop appears to be continuous and saucer shaped apart from a clear bulge centre left. Stereo plots represent measurements of a number of sillhosted conjugated faults/fractures for three localities. Circle $=\sigma_{1}$, diamond $=\sigma_{2}$ and square $=\sigma_{3}$. The two small spherical images illustrate examples of conjugate thrust faults, commonly occurring at various scales in many parts of this sill. b) Same as in a), but from a different angle and altitude. It appears obvious that the bulge appearing in a) results from a tongue-shaped protrusion relative to the rest of the profile of the transgressive Streymoy Sill. Semi-transparent white arrows indicate directions of local sill inclination and hence the most probable propagation direction of initial sill melts.

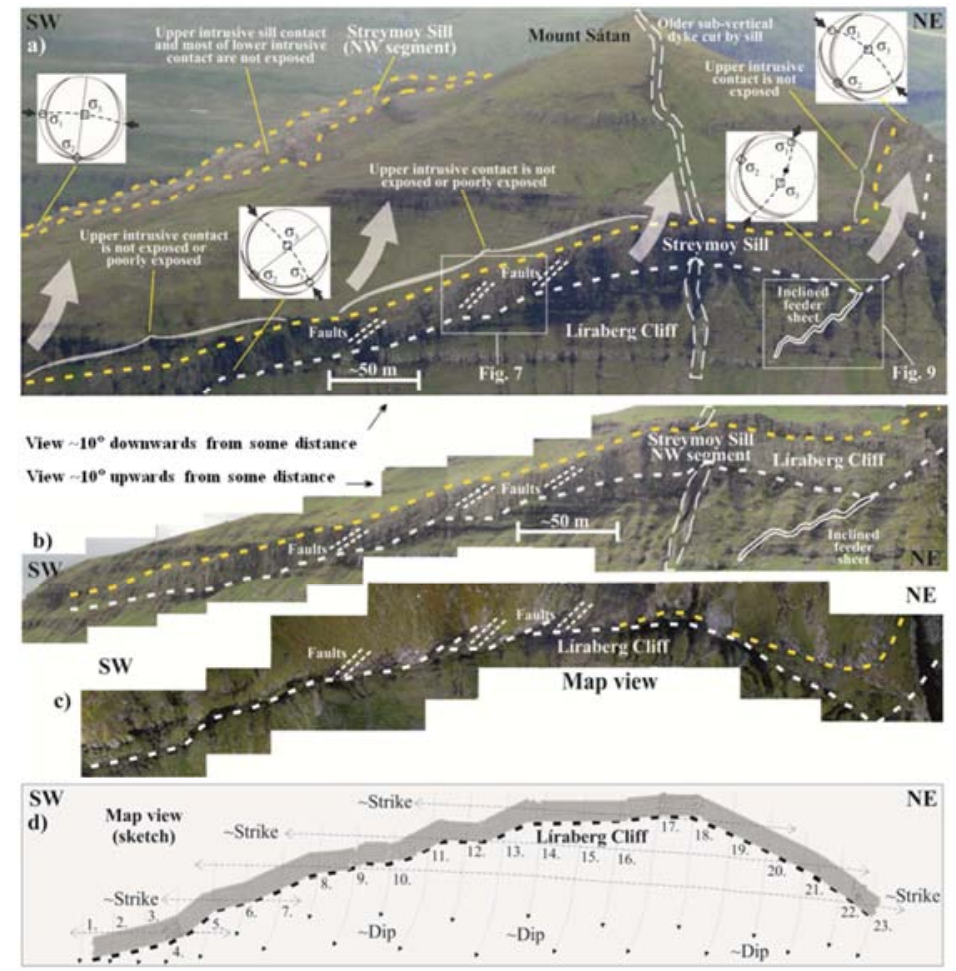

Figure 4. The 1.2 kilometre wide view of the Streymoy Sill, NW segment, at the cliff of Liraberg and Mount Sátan (Figure 1c) is seen here from three different angles. White/yellow dashed lines denote lower and upper sill margins respectively. a) The image, taken at a slight downwards angle from some distance, displays the main features characterising the actual sill profile at this location. Semi-transparent white arrows are sub-parallel to approximate dip directions and hence represent most probable directions of initial magma propagation/climbing. Stereo plots represent measurements of a number of sill-hosted conjugated faults/fractures for three localities and sill-hosted thrust faults versus one local inclined feeder sheet for one locality just on top of the actual feeder sheet. Circle $=\sigma_{1}$, diamond $=\sigma_{2}$ and square $=\sigma_{3}$. b) Same as in a), but this image is taken at a slight upwards angle from some distance. c) The sill profile, which is shown in a) and $b$ ), is presented in aerial view (map view) in this image. It is evident from this combined sub-vertical image, that the sill profile characteristics displayed in a) and b) are more or less mimicked, i.e. each time there are changes in apparent inclination at the lower sill contacts, these can be detected in map view as well. The initial high-resolution drone-based images used in this composite image were provided by Magnus Pauli Joensen, Faroe Islands. d) Sketch of the sill profile from c) with additional information on approximate local strike and dip directions, indicated by dashed and dotted lines respectively. Numbers along dip indicators are intended for references in text below. 
A roughly 1.2 kilometre profile representing the NW segment of the Streymoy Sill, cropping out in the area at the cliff of Líraberg, appears somewhat irregular without noticeably clear-cut saucer-shaped geometries (Figure 4a; Figure $4 \mathrm{~b}$ ). Instead, the actual profile displays a gradual gentle, but slightly irregular, climbing from left to right for $3 / 4$ of the distance and then it apparently descends at a moderate angle for around 100-150 metres towards the right until it apparently abruptly ascends almost sub-vertically until out of sight (Fig, 4a). In this context it is pertinent to note, that if the magmas, which gave rise to the actual sill, initially propagated at roughly right angles with local strike directions and approximately according to the white arrows in Figure $4 \mathrm{a}$, only relatively smaller components of these magmas would have climbed from right to left in Figure $4 \mathrm{a}$ and Figure $4 \mathrm{~b}$, while larger melt components would have proceeded at an inclined angle away from the observer.

It is noticeable that only relatively restricted parts of the lower sill contact occur as "sub-horizontal steps/flats", being sub-parallel to estimated strike directions, while most of the left and middle sections of this transgressive sill display positive slopes and the right section largely displays negative slopes, relative to local strike directions (Figure 4d).

\subsection{Medium-scale Sill Structures (Tens or Hundreds of Metres Scales)}

A closer look at sections of the large transverse sill profile from Figure 3a reveals that the seemingly continuous lower sill margins on either side of the conspicuous bulge appear to be somewhat irregular after all.

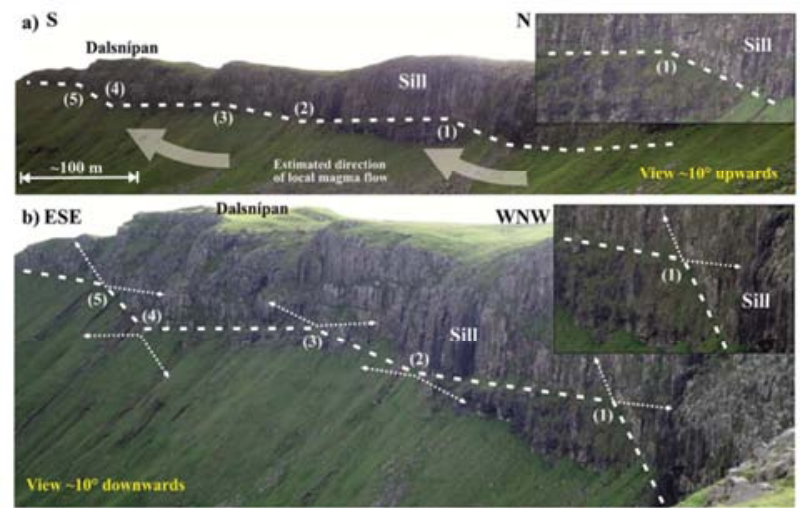

Figure 5. Part of the Streymoy Sill, SE segment, cropping out adjacent to the village of Norðadal (see also Figure 3a). Lower sill contacts are indicated with white dashed lines. a) Image, taken slightly upwards and roughly orthogonal to the bulk of the cliff face, showing apparent ramp-flat geometry at the lower sill contact. Intersections are numbered. Most probable propagation paths of initial sill melts are indicated with large white arrows. b) Same as in a), but taken slightly downwards and at a different location at a narrower angle with the cliff face. The sill contact/base changes direction in map view at each intersection between ramps and flats, as indicated with numbers. Extrapolated directions of individual sill base sections are indicated with small white dotted arrows.

The roughly north-south sill profile at Dalsnípan apparently displays relatively large gentle ramp-flat geometries in its entirety, when seen from some distance broadly orthogonal the cliff face (Figure 5a). However, a closer examination from another point of view at a more narrow angle with the cliff face and with the actual image being taken at a slight downwards angle demonstrates, that each transition from ramp to flat or vice versa generally involve direction changes in map view of the lower sill margin by as much as $\geq 20^{\circ}$ as well (Figure $5 b$ ).

The roughly east-west directed and relatively steeply inclined sill profile exposed in the area at Mount Núgvan displays an irregular lower margin in a manner comparable to that of the profile from Figure 5, but with smaller and much less regular structures (Figure 6). Images portraying this sill profile from various locations and at various angles indicate, that these irregularities by and large are associated with comparable deviations in the lateral plane as well, which can clearly be detected in Figure $6 \mathrm{~b}$ and Figure 6c. It appears reasonable to assume that differences in erosion rates played a dominating role in the examples illustrated in Figure 6, where slightly protruding parts represent relic sill material relative to the generally more continuous sill front, while dents in the sill front most likely represent the opposite scenario, i.e. such dents exemplify sill parts that are slightly more eroded relative to the more continuous sill front. It is noticeable that the nature of the host-rocks apparently had some effect on the actual erosion rates, as illustrated at the lower sill margin in the Norðadal area, Faroe Islands. Successions of relatively thick homogeneous resilient tabular lava flows seem to have generated conditions favouring more or less continuously sloping lower sill margins, while successions of thin compound lava flows generated conditions favouring erosion and the formation of flat structures at lower sill margins, e.g. adjacent to (3) and (4) in Figure 6.

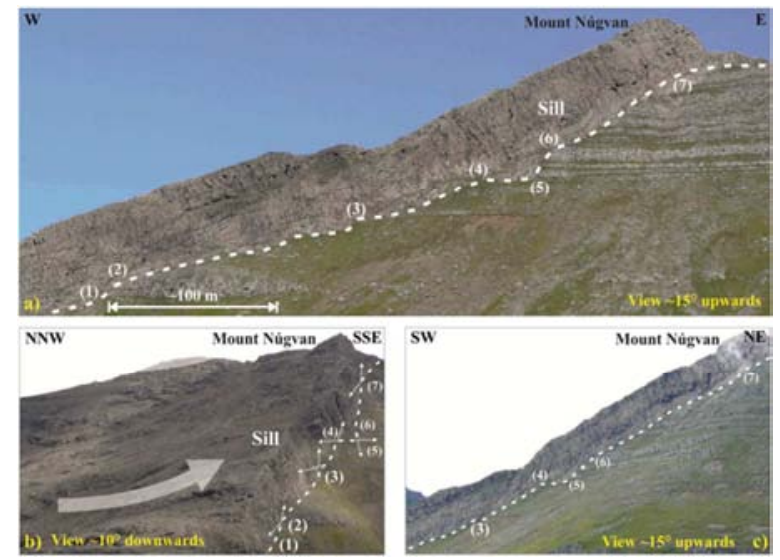

Figure 6. Part of the Streymoy Sill, SE segment, which crops out at Mount Núgvan (see also Figure 3a). Lower sill contacts are indicated with dashed white lines. a) Image, taken roughly orthogonal to the cliff face, but at a slight upwards angle and showing apparent irregular (ramp-flat) geometry at lower sill contact. Most intersections are numbered. b) Same as in a), but taken slightly downwards and at a narrow lateral angle with the cliff face. Large white arrow indicates the most probable propagation direction of initial sill magmas. Extrapolated directions of individual sill base sections are indicated with small white dotted arrows. c) Same as in a) and b), but taken at a slight upwards angle and a lateral angle of around $30^{\circ}$ with the cliff face. 
Parts of the broadly NE-SW directed slightly inclined sill profile in the Líraberg area, as shown in larger scale in Figure $4 \mathrm{a}$ and Figure $4 \mathrm{~b}$, display apparent ramp-flat geometries when observed orthogonal to the cliff face (Figure 7a). Apart from the smaller scales, the individual sections of this outcrop display geometries closely resembling those illustrated for the Norðadal area as shown in Figure 5a. When the actual outcrop is visualised in map view, it is abundantly clear that each intersection between ramps and flats from Figure $7 \mathrm{a}$ is associated with a comparable change in lateral direction of the sill base at the very same locations (Figure 7b). Utilising extrapolation (small white dotted arrows), the general angular changes in lateral directions between ramps and flats at the sill base are estimated at $\geq 20^{\circ}$.
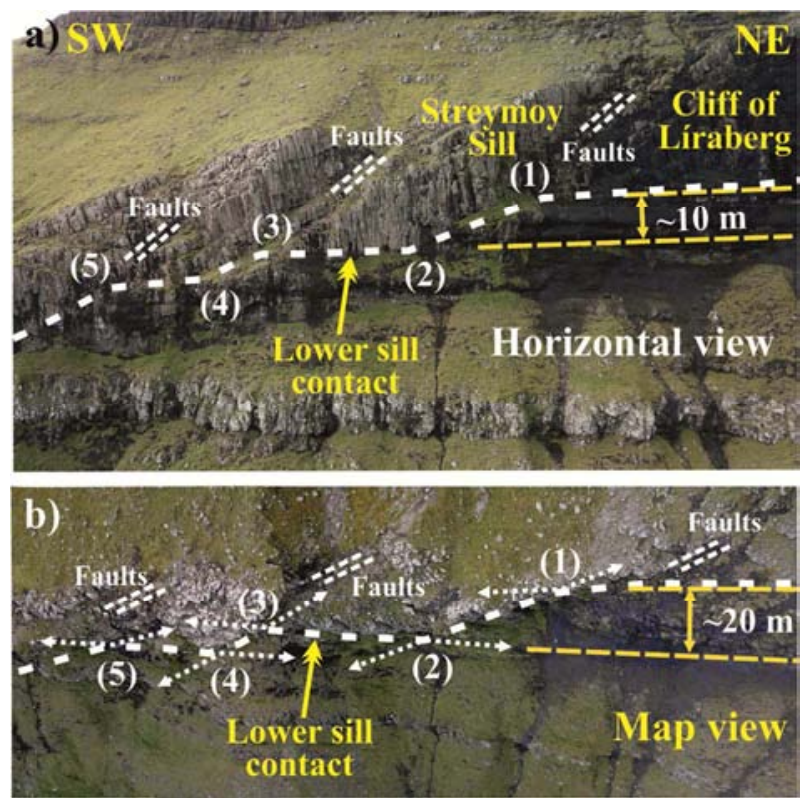

Figure 7. Part of the Streymoy Sill, NW segment, cropping out at the cliff of Liraberg (see also Fig. 4a). Lower sill contacts are indicated with white dashed lines. High-resolution drone-based images building up these two main composite images were provided by Magnus Pauli Joensen, Faroe Islands. Estimated initial magma propagation/climbing directions in this area are indicated in Fig. 4a. a) Image, taken horizontally roughly orthogonal to the cliff face, showing apparent ramp-flat geometries at the lower sill contact. Intersections between ramps and flats are numbered. b) Same as in a), but taken vertically downwards (map view). Extrapolated directions of individual numbered basal sill sections are indicated with small white dotted arrows.

As illustrated in Figure 4, the estimated dip direction and hence very probably also the climbing direction of the initial sill melts at this location transgressed away from the viewer and slightly to the right. A closer examination of the basal sill section from intersections (3) over (2) to (1) and then further to the right, as shown in Figure $7 \mathrm{a}$, demonstrate that a vertical elevation increase of $\sim 10$ metres of the apparent ramp from (2) to (1) is associated with a lateral displacement from (2) to (1) of $\sim 20$ metres (Figure $7 \mathrm{~b}$ ). It would be practically impossible to detect such vital 3-D associations in conventional images taken sub-laterally from some distance by means of a normal digital camera and a zoom lens, which in terms could have imperative effects on correct interpretations with respect to intrusive mechanisms in action during emplacement of such sheet intrusions.

Smaller and even much smaller structures at lower sill margins comparable to those illustrated in previous figures are widespread at various small-scale outcrops in other parts of these same sills as well.
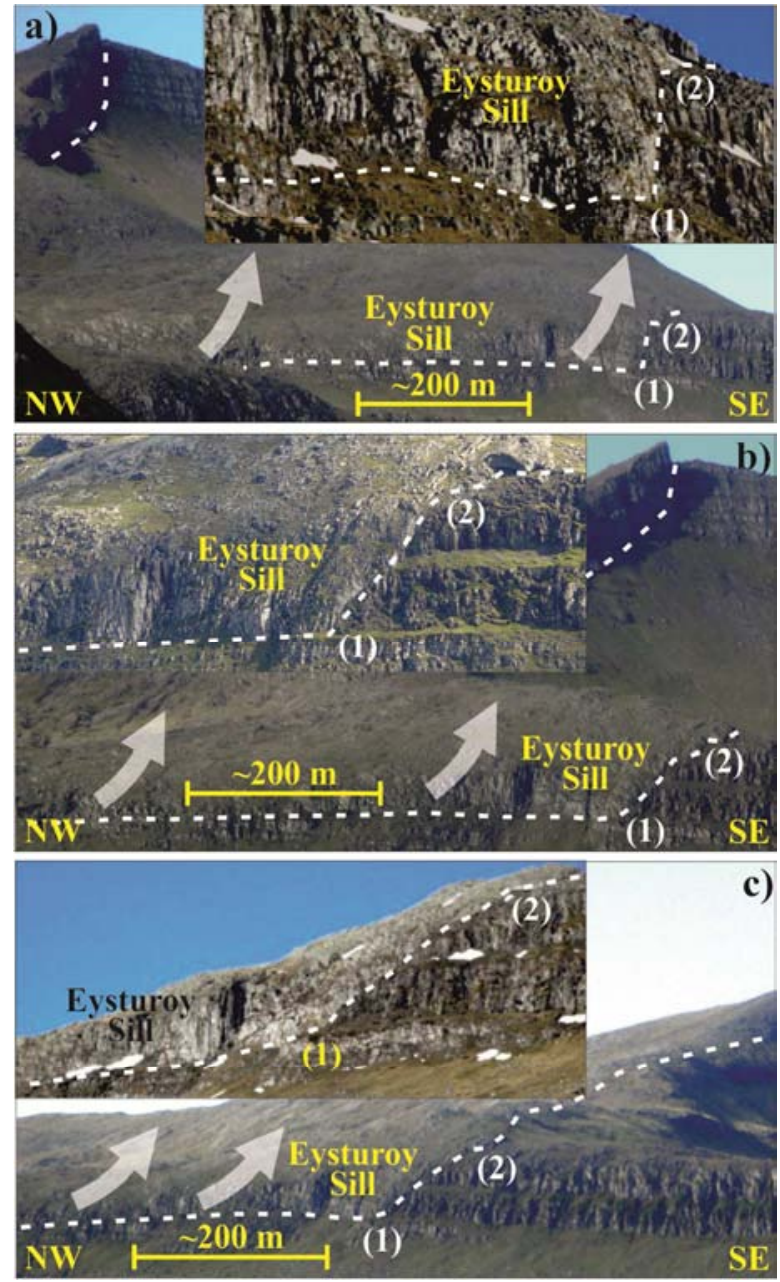

c)

Figure 8. The images represent a part of the Eysturoy Sill, SE segment, cropping out at the village of Selatrad on the island of Eysturoy, Faroe Islands. Images are taken at various sub-lateral angles from some distance (main images) as well as more close-up versions of the same (insets). White dashed lines indicate lower sill margins. Numbers (1) and (2) indicate main reference points. The angular change in lateral direction (map view) of the lower sill margin to the NW of point (1) as compared to the lower sill margin from points (1) to (2) is around $60^{\circ}$. The lower sill margin to the NW of point (1) is sub-parallel to the local strike direction. Semi-transparent white arrows indicate estimated propagation/climbing directions of transgressive sill magmas. a) Image, taken at a lateral angle of around $30^{\circ}$ to the $\mathrm{NW}$ relative to the cliff face at point (1), indicates an apparent sub-vertical climbing of the lower sill margin between points (1) and (2). b) Image, taken roughly orthogonal to the cliff face at point (1), indicates a broadly $50^{\circ}$ degree climbing of the lower sill margin between points (1) and (2). c) Image, taken at a lateral angle of around $30^{\circ}$ to the $S E$ relative to the cliff face at point (1), indicates a roughly $30^{\circ}$ degree climbing of the lower sill margin between points (1) and (2).

The NW-SE oriented panorama views in the part-figures of Figure 8 fittingly illustrate another conspicuous scenario not uncommonly encountered in transgressive sill settings. In 
the image of Figure $8 \mathrm{a}$, taken in the sub-lateral plane at a slightly oblique angle $\left(\sim 30^{\circ}\right)$ with the cliff face from the NW of point (1), the lower sill margin apparently climbs at an angle of $\sim 90^{\circ}$ (i.e. sub-vertically) between points (1) and (2). In the image of Figure 8b, also taken in the sub-lateral plane roughly orthogonal to the cliff face to the NW of point (1), the lower sill margin apparently climbs at an angle of $\sim 50^{\circ}$ between points (1) and (2). Finally, in the image of Figure 8c, taken in the sub-lateral plane at a slightly oblique angle $\left(\sim 30^{\circ}\right)$ with the cliff face from the SE of point (1), the lower sill margin apparently climbs at an angle of $\sim 30^{\circ}$ between points (1) and (2). It appears abundantly clear that visual observations involving margins of transgressive sills in rugged mountainous terrains can be greatly influenced by the exact location, in which the observations are obtained from. It is noteworthy that the apparent sub-vertical climbing at the lower sill margin, as shown for the Eysturoy Sill between points (1) and (2) in Figure 8a, broadly resembles the more large-scale scenario indicated for the Streymoy Sill, as seen at the centre right in Figure 4a. The same is true for intersection (1) in Figure 5. It is conspicuous that the lower sub-lateral sill margin to the NW of point (1) in Figure 8 is more or less aligned with a thin host-rock layer, which is presumably weaker mechanically when compared with the two thick resilient host-rock lava flows resting on it. In this context it is important to note however, that it is highly unlikely that the initial sill magmas propagated parallel to this sub-lateral relatively weak host-rock layer from the NW towards the SE, rather these melts very probably climbed at some angle across the actual layer, presumably in a manner broadly according to the white arrows shown in Figure 8 . Comparable scenarios are envisaged for the sill outcrops at Líraberg and at the Norðadal area, as shown in previous figures.

\subsection{Inclined Feeder Sheets}

A number of inclined sheets, which initially fed some of the saucer-shaped basaltic sills of the Faroe Islands, have been detected hitherto, including the nicely exposed feeder to part of the NW segment of the Streymoy Sill at the cliff of Líraberg. The actual feeder sheet crops out in steeply sloping terrain characterised by alternating ridges and gullies, oriented sub-parallel to the local slope direction, where it generally ascends at a moderate average angle from the WSW towards the ENE (from left to right). A noticeable feature characterizing this inclined feeder includes its irregular undulating geometry, which can easily be taken for a ramp-flat structure, when seen from some distance and at slight upwards angles, as the feeder appears to climb towards local ridges and to descend towards local gullies in a weakly sinuous manner (Figure 9a). However, when seen at slight downwards angles from some distance or in map view, this same feeder appears to display exactly opposite features, i.e. climbing towards local gullies and descending towards local ridges in a sort of sinuous manner (Figure 9b; Figure 9c). The actual feeder generally displays a dip of $\sim 20^{\circ}$ towards $215^{\circ}$, i.e. generally displaying a $\sim$ ESE directed strike.
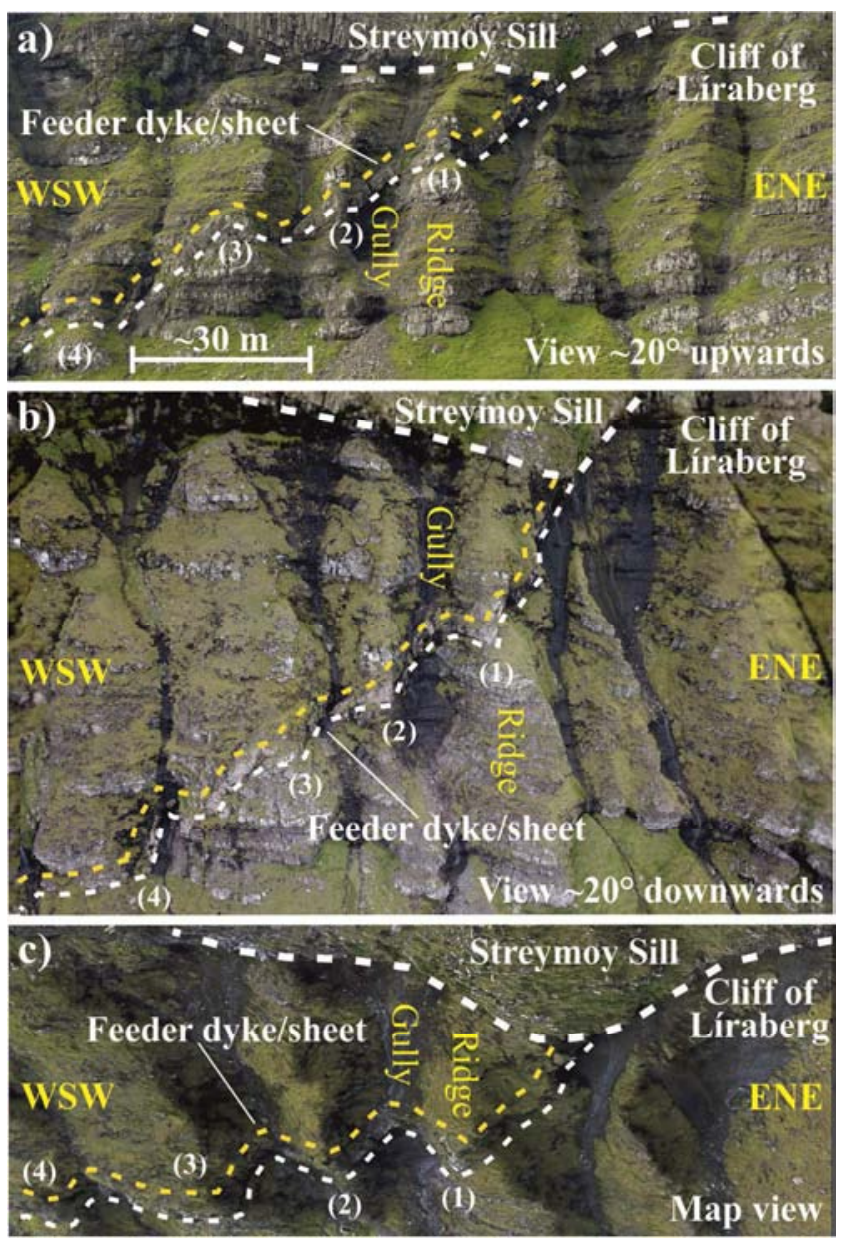

Figure 9. The images illustrate an inclined sheet that initially fed the $\mathrm{NW}$ segment of the Streymoy Sill at the current cliff of Liraberg (See also Fig. 4a). White dashed lines indicate lower margins of feeder sheet and sill, while yellow dashed lines indicate upper margins of feeder sheet. Numbers along the feeder indicate ridges traversed by the feeder sheet. High-resolution drone-based images b) and c) were provided by Magnus Pauli Joensen, Faroe Islands. a) Image taken from some distance at a slight upwards angle. b) Drone-based image taken at a slight downwards angle from some distance. c) Drone-based image taken vertically (map-view).

\subsection{Lava Flows}

Apart from areas covered by debris and vegetation or at sub-vertical cliff faces, lava flows are exposed to various degrees in many parts of the Faroe Islands. In many instances, flows most resilient to erosion and weathering can be seen as sub-horizontal and sub-parallel layering on hillsides or on mountainsides (E.g. Figure 10a). Not uncommonly, such seemingly sub-horizontal lava layers can be traced for substantial distances in gently or steeply, but homogeneously, sloping landscapes. However, occasionally convergent or divergent lava flows appear in rugged terrains of this archipelago, particularly when observed at various upwards angles (E.g. Figure 10b). According to common physical and geological principles, convergent or divergent lava flows could in theory result, if their magma sources originated from different locations and perhaps propagated in different directions as well. 

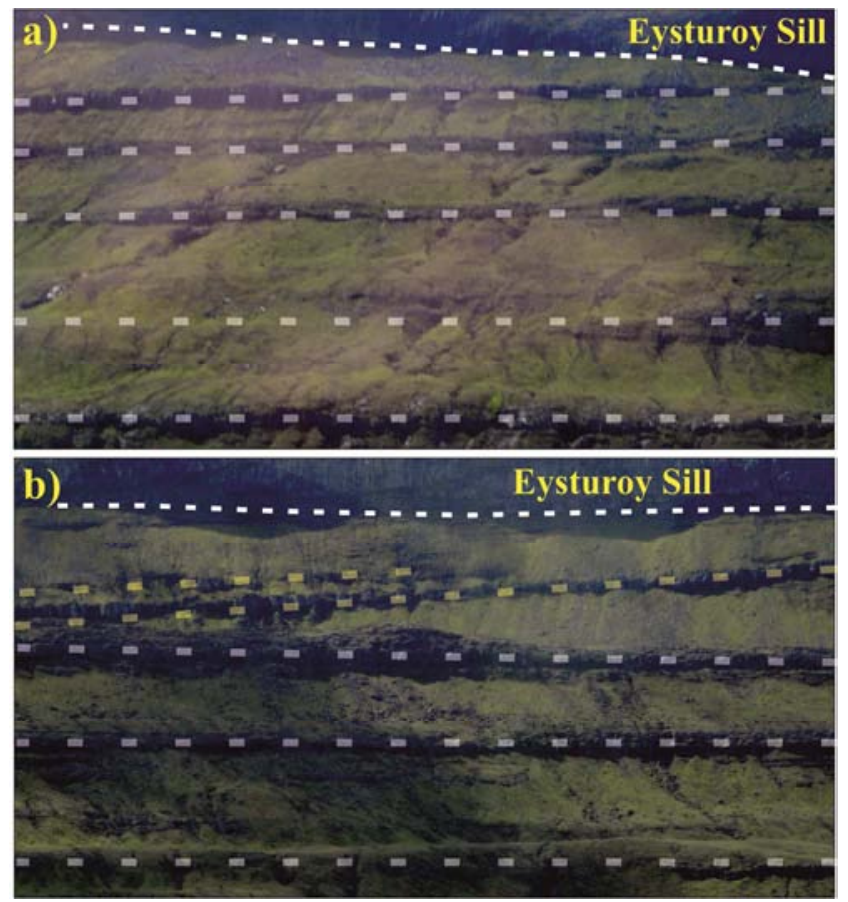

Figure 10. Basaltic lava flows of the Faroe Islands. Thinner white dashed lines indicate lower margins of a local sill. Thicker semi-transparent white and yellow dashed lines indicate local lava flows. a) All visible lava flows display sub-lateral and sub-parallel orientation (thick white semitransparent dashed lines). b) The three lowermost lava flows display subparallel and sub-lateral orientation (thick white semi-transparent dashed lines), while the two topmost lava flows display converging orientations relative to the sub-lateral ones (thick yellow semi-transparent dashed lines).

\section{Discussion}

\subsection{Stress Regime During Sill Emplacement}

One of the physical factors not uncommonly thought to have the potential to affect intrusive mechanisms, when it comes to sill emplacement, includes the prevailing local or regional stress regime $[14,17]$. According to general principles in structural geology, extensive stress regimes produce relatively steep normal faults, whereas compressive stress regimes generally produce less steep thrust faults [21].

In this context it is relevant to note that as general rule $\sigma_{1}$ plots at or near the centre of stereo plots for normal faults, while $\sigma_{3}$ plots at or near the centre and $\sigma_{1}$ plots near or on the primitive for thrust faults. According to general laws of physics and hydraulics, pressurised low-viscosity intrusive fluids/magmas propagating in e.g. compressive stress regimes should be expected to be channelled through potential pre-existing thrust faults or any other relatively weak crustal structures in preference to surrounding homogeneous solid host-rocks at shallow crustal levels.

With respect to conjugated thrust faults hosted by the Streymoy Sill, it is noticeable that only few or perhaps none of these can be correctly measured from some distance by means of e.g. a digital camera and a zoom lens aided by a compass and/or a topographical map in places, where these are exposed on sub-vertical (two dimensional) cliff faces, as these faults hardly ever intersect such cliff faces at right angles. When it comes to the timing of sill-hosted thrust faults in any sills, these must per definition have developed in post-magmatic environments, as only completely solidified magmas have the potential of brittle fracturing. Hence, these are only valid as local or regional stress indicators at the time of sill intrusion, if the actual stress regime lasted at least during the entire time interval of magma intrusion and solidification.

It is noticeable that structural measurements involving various conjugated thrust fault systems/sets and feeder-fault systems hosted by the Streymoy Sill almost invariably differ from location to location even if these may be situated only a few hundred metres apart, as presented in Figure $3 \mathrm{a}$ and Figure 4a. It is noticeable too that local strike and dip directions in areas at and around Líraberg and Norðadal (presented in Figure 3 and Figure 4), in general vary in a way that would be expected for the inner parts of saucer-shaped sills, i.e. dips are more or less radiating towards sort of a central area while the local strike directions vary accordingly.

Altogether, the structural measurements performed in this work and in Hansen (in prep.) of sill-hosted thrust faults and feeder sheets occurring in the Streymoy Sill do not point to any unidirectional regional or local shortening during sill emplacement, although measurements of these sill-hosted conjugated faults clearly point to shortening at the local scale. Rather, the Streymoy Sill likely experienced multidirectional thrust/pressure during emplacement, particularly following crystallisation of its parental magmas (Hansen, in prep.).

\subsection{Apparent ramp-Flat Geometries and Understanding Intrusion Mechanisms}

As demonstrated in the previous section, correct interpretation of intrusion mechanisms, associated with sill emplacement based on field evidences, relies heavily on the approach taken, when it comes to the acquirement of suitable field data, be it by means of digital cameras/images including the use of zoom lenses or any other comparable methodology. In order to avoid unfortunate misinterpretations when it comes to visual observations of e.g. a sill intrusion, it is imperative as a start to ascertain if it is wholly or partly transgressive and if yes, to carefully measure slope/dip and strike directions on a suitable number of pertinent sites. Likewise, it is essential to read the entire landscape (including host-rocks) correctly if possible, i.e. to properly include 3-D considerations in the complete interpretations.

With the purpose of demonstrating, investigating, interpreting and properly explaining the characteristics not un-commonly observed at margins of igneous sheets in the rugged terrains of the Faroe Islands, as presented in the previous section, a closer look at the optical peculiarities, which may negatively affect visually-based interpretations of intrusion mechanisms in action during emplacement of these sills, appears to be appropriate.

When it comes to transgressive sills, a few main optical scenarios can be envisaged, which have the potential to 
significantly influence the appearance such intrusions display to observers at some distances in the sub-lateral plane. Starting with imagined sills seen from atop (map view) and chosen dips somewhere in the range from $15^{\circ}$ to $25^{\circ}$, three simple circumstances can explain much of the scenarios illustrated/presented in the previous section. 1) The lower sill margin has an eroded front that is sub-parallel to local strike direction (Figure 11a); 2) the lower sill margin has an eroded front that displays a positive slope with an angle $\theta$ relative to the local strike direction (Figure 11b) and 3) the lower sill margin has an eroded front that displays a negative slope with an angle $\theta$ relative to the local strike direction (Figure 11c). If the situation in Figure 11b is considered first, using conventional trigonometry and a strike length of $10 \mathrm{~m}$ and an angle $\theta$ of $25^{\circ}$, the calculated lateral distance between Strike ${ }^{\mathrm{L}}$ and Strike $^{\mathrm{U}}$ (map view that is) is $4.66 \mathrm{~m}$ and the length of the actual sloping lower sill margin is $11.03 \mathrm{~m}$ (Figure 11d). Obviously, if a lesser angle $\theta$ is chosen, then the calculated distances would be lesser. Taking the results from Figure 11d further on, but using an alongstrike view and conventional trigonometry again and a lateral distance between $\mathrm{Strike}^{\mathrm{L}}$ and
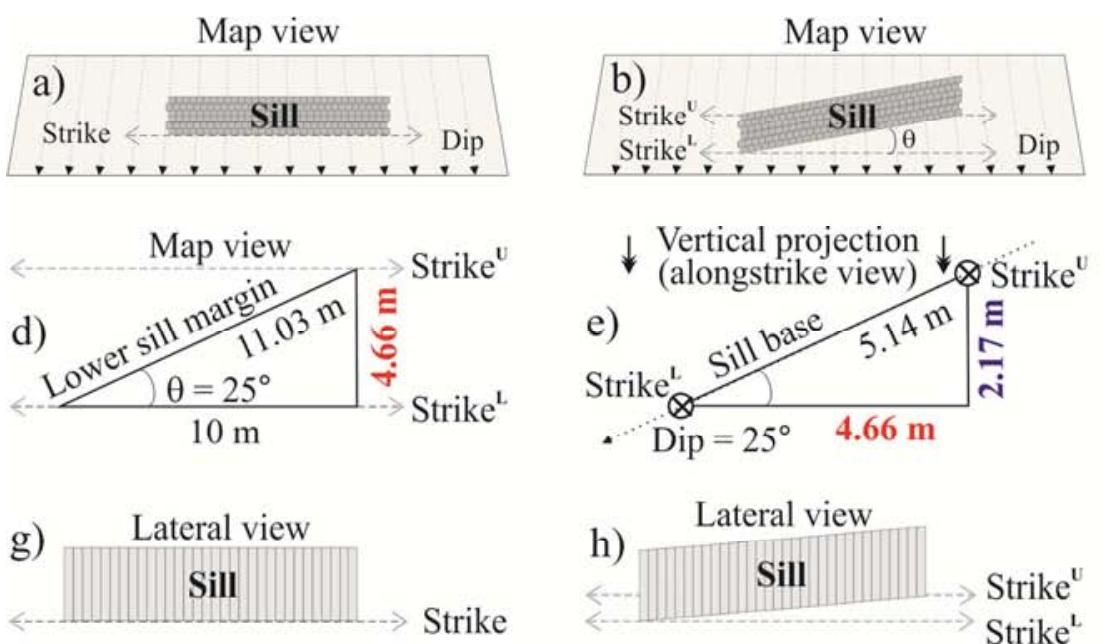

Map view
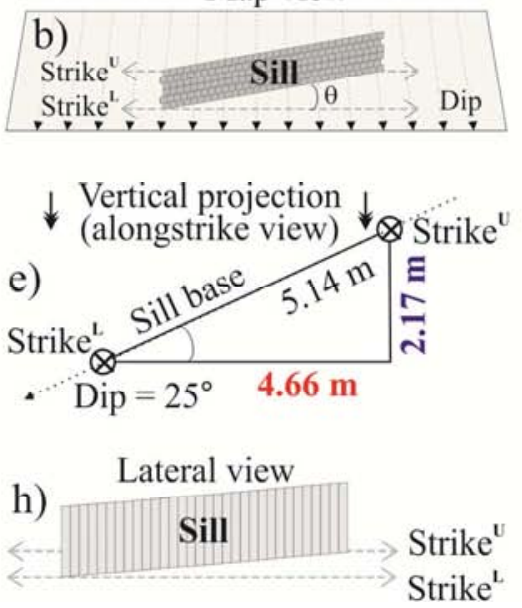

Strike $^{\mathrm{U}}$ of $4.66 \mathrm{~m}$ (from Figure 11d) and a dip of $25^{\circ}$ for the sill base, the calculated vertical distance between Strike $^{\mathrm{L}}$ and Strike $^{\mathrm{U}}$ is $2.17 \mathrm{~m}$ and the length of the sill base from Strike ${ }^{\mathrm{L}}$ to Strike $^{\mathrm{U}}$ is $5.14 \mathrm{~m}$ (Figure 11e). When doing the same calculations, as shown in Figure 11e, over again, but using a dip of $20^{\circ}$ for the sill base, the calculated vertical distance between Strike ${ }^{\mathrm{L}}$ and $\mathrm{Strike}^{\mathrm{U}}$ would be $1.7 \mathrm{~m}$ and the length of the sill base from Strike ${ }^{\mathrm{L}}$ to Strike $^{\mathrm{U}}$ would be $4.96 \mathrm{~m}$ (Figure 11f). Hence, for an angle $\theta$ of $\sim 25^{\circ}$ and a dip of $\sim 25^{\circ}$, the vertical distance between Strike $^{\mathrm{L}}$ and Strike $^{\mathrm{U}}$ is approximately $1 / 2$ of the lateral distance between $\operatorname{Strike}^{\mathrm{L}}$ and Strike $^{\mathrm{U}}$ (Figure 11e), while for an angle $\theta$ of $\sim 25^{\circ}$ and a dip of $\sim 20^{\circ}$, the vertical distance between Strike ${ }^{\mathrm{L}}$ and $\mathrm{Strike}^{\mathrm{U}}$ is slightly larger than $1 / 3$ of the lateral distance between Strike ${ }^{\mathrm{L}}$ and Strike ${ }^{\mathrm{U}}$ (Figure 11f). Consequently, sequentially lesser angles $\theta$ and/or lesser dip angles in continuously transgressive sill intrusions in mountainous terrains would produce sequentially less conspicuous apparent bends or ramp -flat geometries when observed in the sub-lateral plane from some distance.
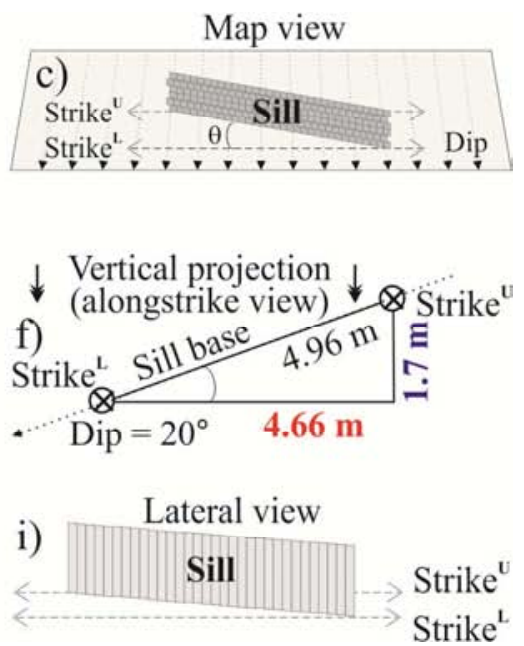

Figure 11. The sketches in a), b) and c) represent three theoretical sill sections in map view where the sills initially had dips of a few degrees ( $15^{\circ}$ to $25^{\circ}$ ), as indicated with thin dotted arrows. Strike directions are indicated with thin dashed arrows. In a), the eroded sill front is parallel to the strike direction. In b), the eroded sill front slopes positively $(\theta)$ from a lower strike (Strike ${ }^{L}$ ) to an upper strike (Strike ${ }^{U}$ ). In c), the eroded sill front slopes negatively ( $\left.\theta\right)$ from an upper strike (Strike ${ }^{U}$ ) to a lower strike (Strike ${ }^{L}$ ). d) Scenario in map view from b) where $\theta$ is chosen to be $25^{\circ}$ and the distance of the sloping sill front projected to the lateral Strike $e^{L}$ measures $10 \mathrm{~m}$. Using conventional trigonometry the calculated length of the sloping sill front and the lateral distance from Strike ${ }^{L}$ to Strike are indicated on the diagram. e) The sill from d) is seen here in an alongstrike view where a sloping sill base of $25^{\circ}$ (chosen dip value) is projected to the lateral distance Strike ${ }^{L}-S_{\text {Stike }}^{U}$, as calculated in d). Again using trigonometry the vertical distance between Strike ${ }^{L}$-Strike $e^{U}$ is calculated, as indicated in the diagram. f) Same as in e), but using a chosen dip value of $20^{\circ}$. g) Lateral view of a). h) Lateral view of b). i) Lateral view of c). See text for further explanation.

Inferences from the actual trigonometric computations are demonstrated in other part figures of Figure 11, where the sketch in Figure $11 \mathrm{~g}$ illustrates a sub-lateral view of the scenario in Figure 11a, the sketch in Figure 11h illustrates a sub-lateral view of the scenario in Figure $11 \mathrm{~b}$ and the sketch in Figure 11i illustrates a sub-lateral view of the scenario in Figure 11c.

When the calculations presented in Figure 11 in addition to relevant on-site strike and dip measurements are compared with visual observations, as illustrated in the previous section, a few inferences can be made.

With respect to the overall appearance of the transverse sill profile at the cliff of Líraberg, as presented in the part figures of Figure 4 and associated text, most of the observed visual aspects can be explained by means of the calculations shown in Figure 11. If strikes and dips of Figure $4 d$ are compared to the illustrated results in Figure 11, it becomes evident, that the lower sill margin between dip indicators 18-23 compares to Figure 11c and Figure 11i, the lower sill margin between dip indicators 9-10, 11-12 $\frac{1}{2}$ and 17-18 compare to Figure 11a and Figure $11 \mathrm{~g}$ while the other parts of the lower margin of the actual sill profile to various degrees compare to Figure $11 \mathrm{~b}$ and Figure $11 \mathrm{~h}$.

An even clearer picture of the same phenomena is 
illustrated in Figure 7. Here, a sub-lateral view of a small part of the sill profile from Figure 4 is contrasted against a subvertical (map view) image of the same sill part in some more details. It is noticeable that the sub-vertical distance between points (2) and (1) is $10 \mathrm{~m}$, while the lateral distance between these are $20 \mathrm{~m}$. Although the measured distances in this example are only approximate, this scenario is comparable to the results shown in Figure 11e, i.e. the vertical distance between Strike $^{\mathrm{L}}-\mathrm{Strike}^{\mathrm{U}}$ is approximately $1 / 2$ the lateral distance between these.

Similar inferences can be made in relation to apparent ramp-flat geometries when it comes to sill profiles shown in Figure 3, Figure 5 and Figure 6, representing the area around Norðadal. Hence, the manner in which erosion may affect transgressive sills cropping out in rugged mountainous terrains have a great potential to influence the way in which these appear when observed in the sub-lateral plane, particularly when imaged from some distance by means of e.g. digital cameras and zoom lenses or the like.

In the example of Figure 11, sub-vertical observations are contrasted against sub-lateral observations, but observations at various angles entirely within the sub-lateral plane have the potential to noticeably affect the manner in which a sill outcrop appear to an observer at some distance too.

Starting with an imagined sill outcrop as seen in the subvertical plane (map view) with its front eroded so as to appear like a ramp-flat structure (flats are sub-parallel to the local strike direction) and chosen dips somewhere in the range from $\sim 15^{\circ}$ to $25^{\circ}$, three simple circumstances can explain some of the scenarios put forward in the previous section. 1) The ramp structure is seen in the sub-lateral plane and sub-parallel to the direction of its lower margin, as it appears in map view; 2) the ramp structure is seen in the sublateral plane and at an oblique angle $\left(\sim 45^{\circ}\right)$ with the direction of its lower margin, as it appears in map view and 3) the ramp structure is seen in the sub-lateral plane and orthogonal to the direction of its lower margin, as it appears in map view (Figure 12a). In view 1. the lower margin of the ramp structure appears to be sub-vertical to the (distant) observer, in view 2. the lower margin of the ramp structure appears as a relatively steep positive slope to the (distant) observer and in view 3. the lower margin of the ramp structure appears as a relatively gentle positive slope to the (distant) observer.

The sketches shown in Figure 12b, Figure 12c and Figure $12 \mathrm{~d}$ are particularly applicable to the scenarios demonstrated in Figure 8a, Figure $8 \mathrm{~b}$ and Figure $8 \mathrm{c}$ respectively and adequately explain the observed features, i.e. the same lower sill margin can appear both as a sub-vertical form and as a gentle sloping ramp depending on actual points and angles of view. The large-scale sill margin/structure centre right in Figure $4 \mathrm{a}$ can also be adequately explained in terms of the viewpoint of the observer being sub-parallel to the direction of the lower sill margin, i.e. in accordance with Figure $12 \mathrm{~b}$. In fact, many of the ramp-flat configurations displayed by the lower margins of sills from the Faroe Islands can to some degree be visualised differently from different point of views in the lateral plane too.
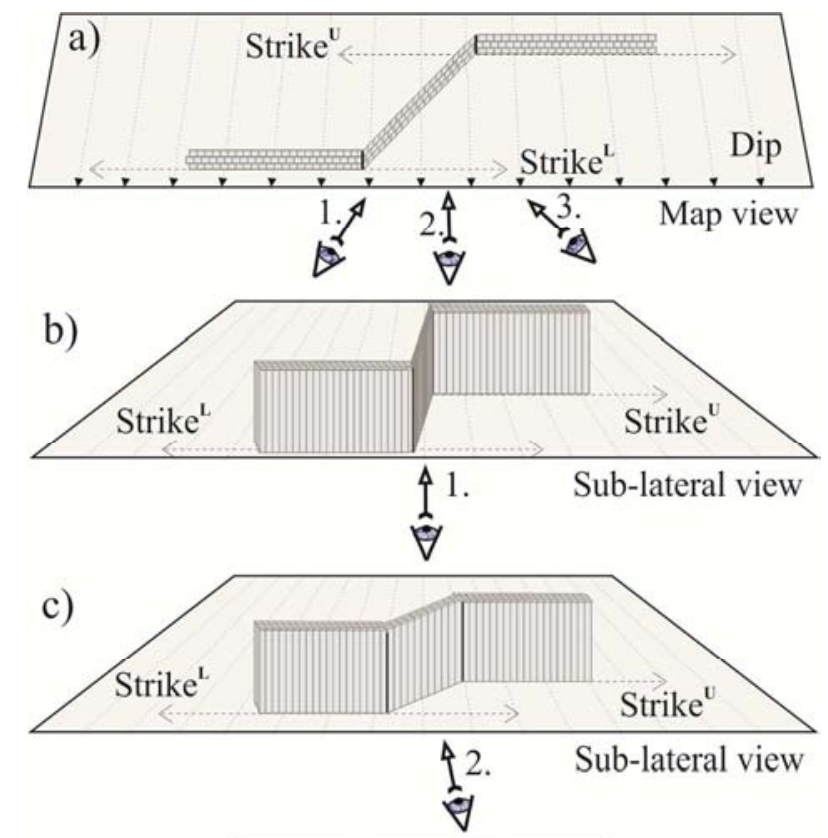

d)

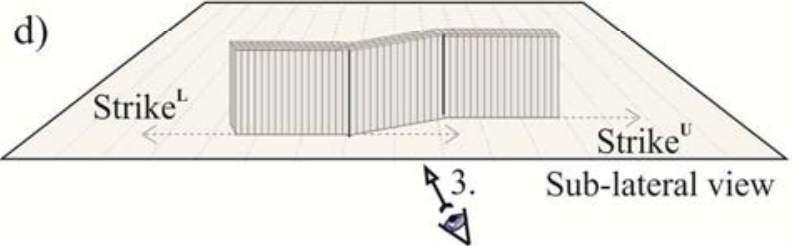

Figure 12. The simplified sketches in this figure demonstrate examples of, how observations from different sub-lateral angles can affect appearances of sill outcrops when viewed from some distance. Small open arrows and eye substitutes represent approximate observing angles in the sub-lateral plane. a) Sub-vertical view (map view) of a transgressive sill outcrop. The model sill displays a moderate dip $\left(15^{\circ}\right.$ to $\left.25^{\circ}\right)$ and the sill front has been eroded to an apparent ramp-flat structure. Dips are indicated with thin dotted arrows and local strike is indicated with thin dashed lines/arrows. Small numbered arrows (1, 2 and 3) and eye sketches suggest three different lateral angles of observation. b) In view 1. the ramp appears as sub-vertical. c) In view 2. the ramp appears as sloping relatively steeply. d) In view 3. the ramp appears as sloping relatively gently.

It is noticeable that ramp structures of lower sill margins in the Faroe Islands commonly appear to be concentrated along zones of mechanically weak sub-horizontal layering, as illustrated in e.g. Figure 4, Figure 7 and Figure 8. However, it is worth noting that in all the examples presented in this study, the initial sill magmas very probably did not propagate sub-parallel to these sub-lateral structures, but rather climbed across these at various inclination angles and at various angles relative to the direction of the fronts of these outcrops, when seen in map view. One explanation for this phenomenon, where sub-horizontal parts of lover margins of transgressive sills are concentrated at mechanically weak host-rock zones would be preferential erosion in relatively mechanically weak host-rock zones, which in turn would result in undermining of the base of the actual sills thus triggering collapse of parts of its front (E.g. Figure 13a).

From section 2 and Figure 1, it is clear that the lava pile of the Faroe Islands is composed of a variety of basaltic products including tabular lava flows, compound lava flows as well as intercalated sedimentary sequences. As evident in 
the landscape at numerous Faroese localities, thin compound lava flows are, in addition to sedimentary sequences, far more prone to erosion when compared to thicker tabular or compound lava flows. Accordingly, some of the flat parts of ramp-flat geometries observed for some parts of Faroese lower sill margins could indeed result from post-glacial erosion of mechanically weak host-rock zones, that resulted in undermining and collapsing of sill fronts at some localities (Figure 13b; Figure 13c).
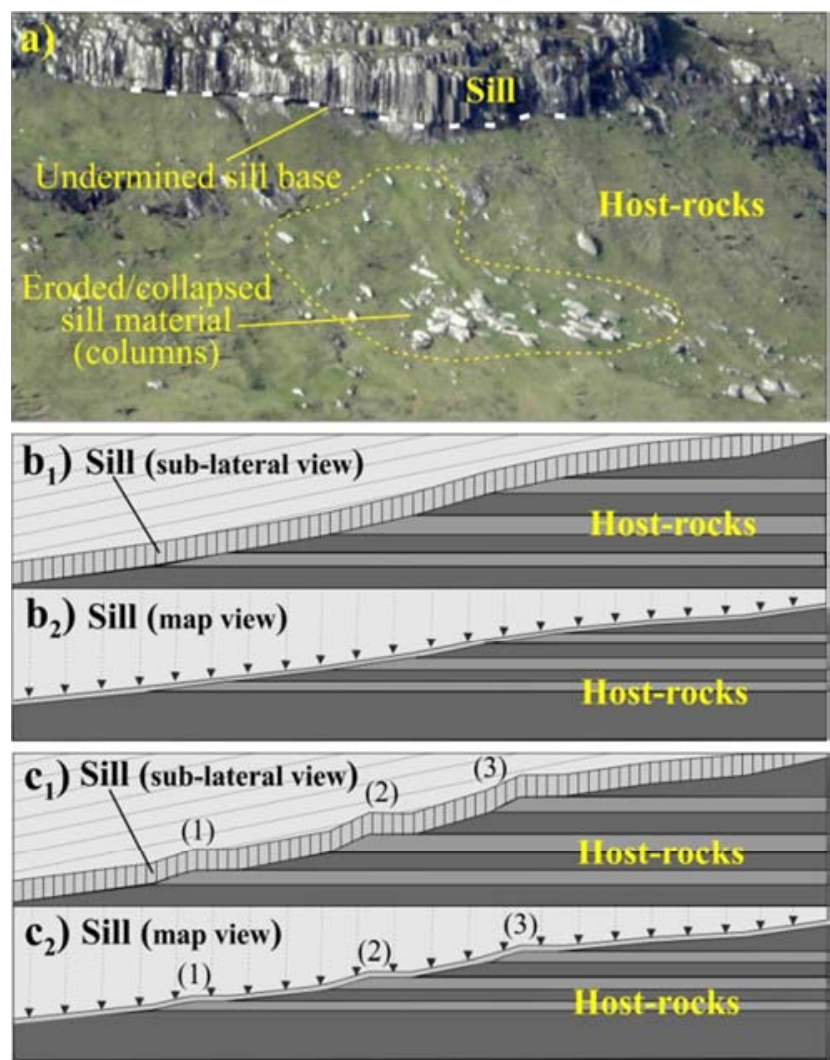

Figure 13. Undermining and erosion at lower sill margins. a) The base and front of a Faroese Sill is undermined and have experienced partial collapse due to erosion of underlying mechanically weak host-rocks. $b_{1}$ ) The simplified sketch shows a sub-lateral view of the front of a transgressive sill and underlying host-rocks of various mechanical competences (dark grey=mechanically stronger, lighter grey=mechanically weaker). $b_{2}$ ) Map view of $b_{1}$ ) with approximate dip directions indicated with thin arrows. $c_{1}$ ) Sections of the sill from $b_{l}$ ) have collapsed due to undermining from erosion of mechanically weak underlying host-rocks thus resulting in ramp-flat geometries at (1), (2) and (3) at sill front. $c_{2}$ ) Map view of $c_{1}$ ) with approximate direction of dips indicated with thin arrows.

Obviously, an interpretation like the one presented here would be slightly at odds with many previous studies involving transgressive sills in e.g. sedimentary settings worldwide (Pls. see section 3 above). It has indeed been demonstrated in quite a few previous studies worldwide, that intrusive magmas not un-commonly are channelled in a ramp-flat fashion along mechanically weak zones and across mechanically stronger zones. Hence, some of the propositions put forward in this study may add some complexity to earlier acknowledged theories, when it comes to sill intrusion into layered strata. However, it would be interesting to test if other sheet intrusions worldwide, which currently have status as ramp-flat intrusions and/or possess sections displaying sub-vertical lower margins/contacts, may owe some of their geometries to the actions of erosion too, as demonstrated above.

When it comes to the ramp-flat or undulating appearance displayed by the feeder sheet to the Streymoy Sill, like demonstrated above, the explanation is rather straightforward. The overall landscape at that particular site is sloping steeply towards $\mathrm{SSE}$ by perhaps $\sim 75^{\circ}$ to $80^{\circ}$. In addition, the actual slope is characterised by a number of alternating ridges and gullies sub-parallel to the general slope direction (Figure 9). If it is assumed that the feeder sheet displays a relatively constant dip and strike for most of its exposed extent (i.e. from around point (4) to the sill base in Figure 14), an observer in the strike plane will see the actual feeder as an inclined more or less straight line in the landscape (Figure 14a). However, when it comes to an observer viewing the feeder sheet from a point well below its strike plane, it displays an undulating geometry with troughs at local gullies and peaks at local ridges (Figure 14b; Figure 2; Figure 9a). Conversely, to an observer situated well above its strike plane, the seemingly still undulating feeder sheet now displays troughs at local ridges and peaks at local gullies (Figure 14c; Figure 9b; Figure 9c). Clearly, to most observers standing on the ground looking upwards at the Cliff of Líraberg, the actual feeder will appear as in Figure 2, Figure $9 \mathrm{a}$ and Figure 14b.
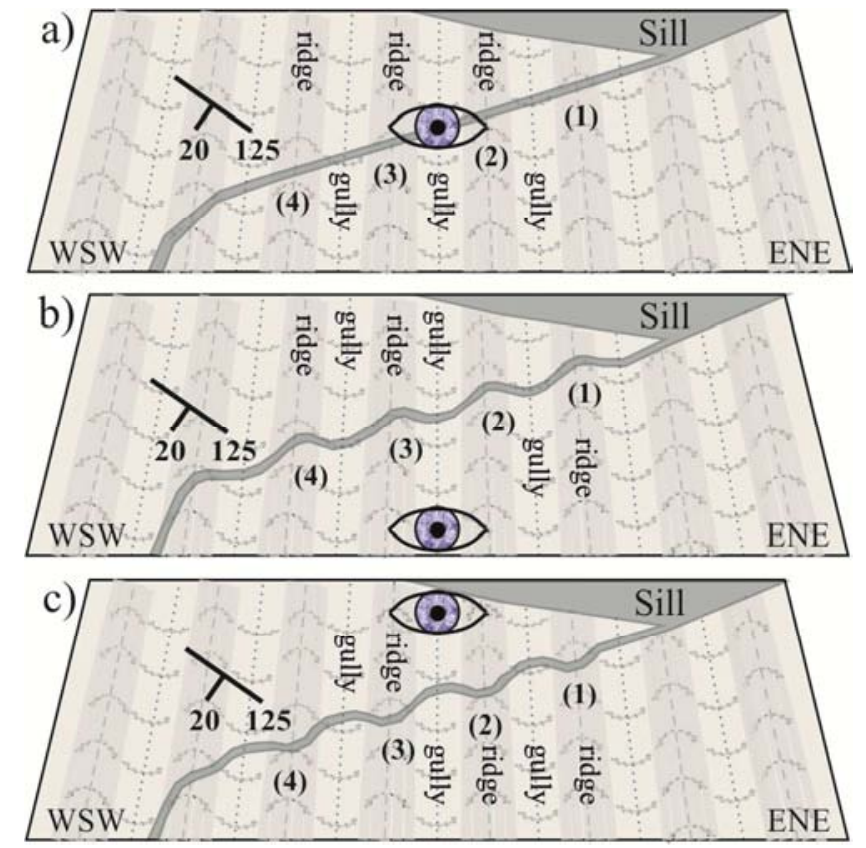

Figure 14. The simplified sketches demonstrate how observations from different angles in the vertical plane can affect visual appearances when it comes to inclined feeders in steep and rugged mountainous terrains. Eye drawings represent relative observation points in the vertical plane. Numbers are indicated for a few local ridges. It is assumed that average host-rocks slope is $70^{\circ}$ to $85^{\circ}$. Structural analyses are indicated (Strike of $125^{\circ}$ and dip of $20^{\circ}$. a) Inclined feeder sheet is observed from within the strike plane. b) Inclined feeder sheet is observed from a plane below the strike plane. c) Inclined feeder sheet is observed from a plane above the strike plane. 
It is worth noting that when it comes to relatively thin sublateral igneous sheets such as feeders or thin sills in general, but also ordinary lava flows, occurring in comparable types of rugged mountainous terrain, as demonstrated in Figure 14, similar visual characteristics of their exposed fronts would be apparent for observers situated at, below or above the strike plane of the actual sheets. Naturally, the difference would be that the average direction of the exposed more or less undulating sheet fronts would be entirely in the sub-lateral plane.

As demonstrated in sub-section 4.4 and Figure 10, lava flows in the rugged mountainous terrains of the Faroe Islands do not un-commonly display apparent converging or diverging geometries in addition to the more normal subparallel ones, particularly when observed at slight upwards angles e.g. through a car window at some local highway. Like it is the case with appearances of both local sills and some of their feeders, the observation of local lava flows from various vertical angles, in addition to on-site examinations/measurements, may result in various outcomes when it comes to their apparent geometries. In Figure 15 an area of the Faroe Islands comprising basaltic rocks apparently contains both sub-parallel and converging lava flows, when observed at slightly upwards angles from some distance. However, when examined in some more details using detailed local topographic data, on-site measurements and examinations in addition to aerial imaging, it becomes evident that the apparent convergence between some lava flows stem from the fact that the relative distance between the observer and lava flows 3 and 4 decrease systematically from profile $\mathrm{A}$ via $\mathrm{B}$ and $\mathrm{C}$ to $\mathrm{D}$, while the distances to lava flows 1 and 2 remains more or less fixed (Figure 15c). The reason for the outcome in this example is that the flat plateau between lava flows 3 and 2, which crops out at an altitude of several hundred metres, cannot be detected unless the observer is situated on spot or at any visible locality within a reasonable distance at even higher altitudes. Hence, the ridge just atop of lava flow 3 progressively closes up to the line of vision from the actual observer of lava flow 2 and 1 as seen from right to left, i.e. from profile A to D (Figure 15c).

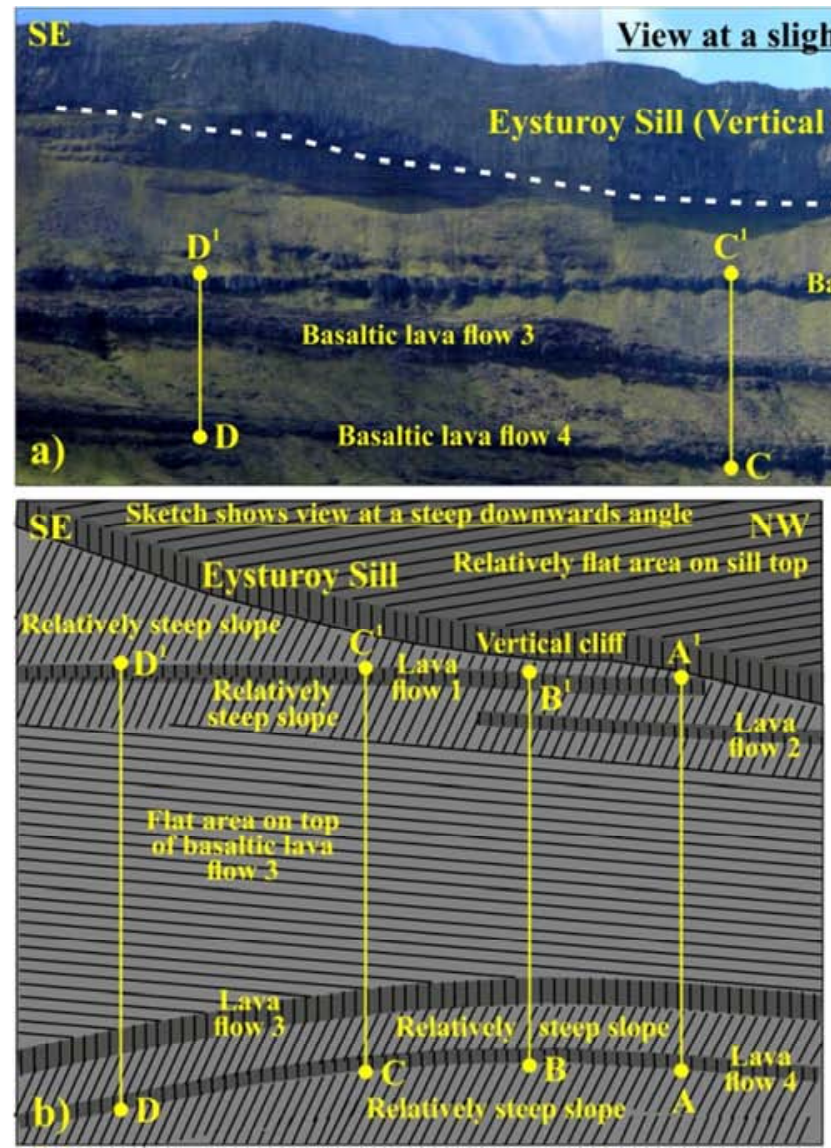


of observation. In turn, the assessed factual geometries of the investigated igneous sheets can be employed in order to interpret/determine the most likely mechanisms of initial magma intrusion, when it comes to intrusive sheet bodies, or if initial magmas building up local lava flow could have been emplaced extruded from/in different directions. In order to support the actual observations, a large number of accompanying in-situ structural measurements were carried out as well.

The findings demonstrated in the text above can be summarised briefly in a few main points:

1. Visual observations from some distance and at various vertical and/or lateral angles of igneous sheet intrusions cropping out in rugged mountainous terrains sometimes yield noticeable dissimilar outcomes, when it comes to the apparent geometries that characterise their main bodies and notably their exposed/eroded margins.

2. In many instances lower margins/contacts of Faroese transgressive sills in rugged mountainous terrains display apparent ramp-flat geometries when viewed at slight upwards angles from some distance, but in reality these generally arise from uneven orientations of their eroded lower margins/contacts, as seen in the subvertical plane (map view). In all the investigated wellexposed lower sill margins/contacts, their initial magmas climbed/transgressed at some vertical and lateral angles across these.

3. Although the lower margins/contacts of the investigated Faroese transgressive sills are not always strictly continuous, notably when it comes to sections subparallel to local strike orientations at their upper rims at higher altitudes, there do not exist any "real" systematic ramp-flat geometries sub-parallel to the initial magma propagation directions in their basal or middle sections, even though the initial sill magmas progressed/climbed through host-rocks of various mechanical competences. Rather, the apparent ramp-flat geometries at lower sill margins of Faroese sills, as observed from some distance, generally turn out to be continuously transgressive and not un-commonly upwards curving over distances of kilometres or hundreds of metres, when examined in more details on-site and viewed from different angles in the vertical and/or lateral plane.

4. Eroded lower margins/contacts of basal or middle sill sections do not un-commonly display sub-vertical geometries when seen from certain angles, but do in reality often possess relatively gentle angles, as observed when different and more appropriate angles of view in the sub-lateral plan are chosen.

5. One can only determine with any degree of certainty if transgressive sheet intrusions display continuous or ramp-flat geometries, when observed from some distance by means of e.g. cameras and zoom lenses, if the actual intrusions crop out in planar sub-vertical and strictly linear cliff faces.

6. Systematic examinations of a Faroese sill feeder show that it displays somewhat sinuous, but oppositely undulating, geometries, when seen at upwards and downwards angles respectively from some distance. However, the actual feeder exhibits a more or less linear geometry, when observed from within its strike plane.

7. Structural measurements of large numbers of sill-hosted conjugate faults do not point to any uni-directional compressive regime in the actual area following crystallisation of the Streymoy Sill, Faroe Islands, which can have caused any uni-directional ramp-flat geometries within the lower margins of local sills, rather this intrusion was exposed to post-crystallisation compressive action from several directions.

8. All sub-lateral lava flows of the Faroe Islands, investigated in this work, which do not un-commonly display apparent converging or diverging geometries, turned out to be sub-parallel in the end.

In conclusion, the actual investigations point to the fact that optical illusion effects can to significant degrees affect the ways; observers discern objects such as eroded margins of sheet intrusions, cropping out in rugged mountainous terrains. It follows that if proper care is not taken by observers to ascertain that observations are acquired from different sites and angles and accompanied by appropriate on-site structural measurements, the end results may involve incorrect interpretations when it comes to e.g. intrusion/emplacement mechanisms and so forth.

In this context it is pertinent to note, that local upper sill margins/contacts are often quite unsuitable as indicators of detailed sill geometries and associated interpretation of intrusion mechanisms, since these commonly are much eroded or partly concealed under debris and/or vegetation, as opposed to lower sill margins/contacts (e.g. Figure 4a).

This paper demonstrates with noticeable probability that initial magmas, building up Faroese sills including the Streymoy Sill, largely progressed and ultimately climbed through their host-rocks in a broadly continuous and radial fashion from one or several feeding sheets or feeding points.

\section{Competing Interests}

The author declares that he has no conflict of interest.

\section{Disclaimer}

The author declares that he has nothing to disclaim.

\section{Acknowledgements}

The inspiration for this paper developed from results obtained in a previous research project in igneous petrology and structural geology carried out at Durham University, UK, and completed in 2011. High-resolution drone images, provided by Magnus Pauli Joensen, Faroe Islands, particularly for this work, are appreciated. The paper benefited from comments by an anonymous senior geologist and from anonymous SciencePG reviewers. Thanks to the Faroese Research Council for providing open access fee. 


\section{References}

[1] Thomson, K. 2007. Determining magma flow in sills, dykes and laccoliths and their implications for sill emplacement mechanisms. Bulletin of Volcanology, 70, 183-201.

[2] Muirhead, J. D., Airoldi, G., Rowland, J. V., White, J. D. L. 2012. Interconnected sills and inclined sheet intrusions control shallow magma transport in the Ferrar large igneous province, Antarctica. GSA Bulletin. 124 (1/2), 162-180. http://dx.doi.org/10.1130/B30455.1.

[3] Hansen J. 2015. A numerical approach to sill emplacement in isotropic media: Do saucer-shaped sills represent 'natural' intrusive tendencies in the shallow crust? Tectonophysics, 664, 125-138. http://dx.doi.org/10.1016/j.tecto.2015.09.006.

[4] Jerram D. A. and Bryan, S. E. 2015. Plumbing systems of shallow level intrusive complexes. In: Breitkreuz, C. H. and Rocchi, S. (eds) Physical Geology of shallow magmatic systems. Advances in Volcanology. Springer, Berlin, 1-22, http://doi.org/10.1007/11157_2015_8.

[5] Buntin, S., Malehmir, A., Koyi, H., Högdahl, K., Malinowski, M., Larsson, S. Å., Thybo, H., Christopher Juhlin, C., Korja, A. and Górszczyk, A. 2019. Emplacement and 3D geometry of crustal-scale saucer-shaped intrusions in the Fennoscandian Shield. Scientific Reports, 9, 10498. https://doi.org/10.1038/s41598-019-46837-x.

[6] Magee, C, Hoggett, M, Jackson, CA-L and Jones, S. M. 2019. Burial-Related Compaction Modifies Intrusion-Induced Forced Folds: Implications for Reconciling Roof Uplift Mechanisms Using Seismic Reflection Data. Fronters in Earth Science, 7, 37. doi: 10.3389/feart.2019.00037.

[7] Magee, C., Muirhead, J. D., Karvelas, A., Holford, S. P., Jackson, C. A. L., Bastow, I. D., Schofield, N., Stevenson, C. T. E., McLean, C., McCarthy, W. and Shtukert, O. 2016. Lateral magma flow in mafic sill complexes. Geosphere, 12 (3), 809-841. doi: 10.1130/GES01256.1.

[8] Chevallier, L. and Woodford, A. 1999. Morpho-tectonics and mechanism of emplacement of the dolerite rings and sills of the western Karoo, South Africa. South African Journal of Geology, 102, 43-54.

[9] Polteau, S., Mazzini, A., Galland, O., Planke, S. and MaltheSørenssen, A. 2008. Saucer-shaped intrusions: Occurrences, emplacement and implications. Earth and Planetary Science Letters, 266, 195-204.

[10] Larsen, H. C. and Marcussen, C. 1992. Sill-intrusion, flood basalt emplacement and deep crustal structure of the Scoresby Sund region, East Greenland. In: Storey, B. C., Alabaster, T. \& Pankhurst, R. J. (eds) Magmatism and the Causes of
Continental Break-up. Geological Society, London, Special Publications, 68, 365-386.

[11] Eide C. H., Schofield N., Jerram D. A. and Howell J. A. 2017. Basin-scale architecture of deeply emplaced sill complexes: Jameson Land, East Greenland. Journal of the Geological Society, London, 174, 23-40. Doi: 10.1144/jgs2016-018.

[12] Burchardt, S. 2008. New insights into the mechanics of sill emplacement provided by field observations of the Njardvik Sill, Northeast Iceland. Journal of Volcanology and Geothermal Research, 173, 280-288.

[13] Gudmundsson, A., Pasquarè, F. A., Tibaldi, A., 2014. Dykes, Sills, Laccoliths, and Inclined Sheets in Iceland. Advances in Volcanlogy. http://dx.doi.org/DOI: 10.1007/11157_2014_1.

[14] Geoffroy, L., Bergerat, F. and Angelier, J. 1994. Tectonic evolution of the Greenland-Scotland ridge during the Paleogene: new constraints. Geology, 22, 653-656.

[15] Hansen, J., Jerram, D. A., McCaffrey, K. J. W., Passey S. R., 2011. Early Cenozoic saucer-shaped sills of the Faroe Islands: an example of intrusive styles in basaltic lava piles. Journal of the Geological Society, London, 168 (1), 159-178. doi: 10.1144/0016-76492010-012.

[16] Hansen, J., Davidson, J. P., Jerram, D. A., Ottley, C. J. and Widdowson, M. 2019. Contrasting $\mathrm{TiO}_{2}$ compositions in Early Cenozoic mafic sills of the Faroe Islands: an example of basalt formation from distinct melting regimes. Earth Sciences, 8 (5), 235-267. http://www.sciencepublishinggroup.com/j/earth doi: $10.11648 /$ j.earth.20190805.11.

[17] Walker, R. 2016. Controls on transgressive sill growth. Geology. doi: 10.1130/G37144.1.

[18] Galland, O., Spacapan, J. B., Rabbela, O., Maira, K., Sotod, F. G., Eikene, T., Schiuma, M. and Leanzag, H. A. 2019. Structure, emplacement mechanism and magma-flow significance of igneous fingers-Implications for sill emplacement in sedimentary basins. Journal of Structural Geology, 124, 120-135. https://doi.org/10.1016/j.jsg.2019.04.013.

[19] Hansen J., 2011. Petrogenetic Evolution, Geometries and Intrusive Styles of the Early Cenozoic Saucer-Shaped Sills of the Faroe Islands. Doctoral thesis, Durham University. http://etheses.dur.ac.uk/3631/.

[20] Gudmundsson, A., 2011a. Deflection of dykes into sills at discontinuities and magma-chamber formation. Tectonophysics, 500, 50-64. doi: 10.1016/j.tecto.2009.10.015.

[21] Hatcher, R. D. 1995. Structural Geology, Principles, Concepts, and Problems. Prentice Hall, Englewood Cliffs, New Jersey, 07632. pp. 525. 